\title{
Using an initial fasting plasma glucose to decrease the need for the Oral GlucoseTolerance Test during pregnancy
}

\author{
Gebelik sırasında Oral Glukoz Tolerans Testi ihtiyacını azaltmak için açlık kan şekeri \\ kullanımı
}

\author{
Osman Şevket*, Seda Ateş*, Gökhan Kılıç*, Taner Molla*, Fulya Özkal*, Ramazan Dansuk*, \\ Sefa Kelekçi**
}

*Haseki Eğitim ve Araştırma Hastanesi, Enfeksiyon Hastalıkları ve Klinik Mikrobiyoloji, İstanbul

**Dumlupınar Üniversitesi, Farmakoloji ve Klinik Farmakoloji Anabilim Dalı, Kütahya

\begin{abstract}
Purpose: To evaluate the utility of initial fasting plasma glucose (FPG) to limit the number of oral glucose tolerance test (OGTT)s needed for the diagnosis of gestational diabetes mellitus (GDM).

Materials and methods: 390 pregnant women (estimated gestational ages 24-28 weeks) were evaluated for GDM using OGTT based on International Association of Diabetes and Pregnancy Study Group (IADPSG) criteria. Two FPG thresholds (of the OGTT) were used to rule in and to rule out GDM.

Results: Using IADPSG criteria, $61(15.6 \%)$ of the participants had GDM. The area the under ROC curve of FPG used to detect GDM was 0.933 . An FPG cut-off value of $\geq 5.1 \mathrm{mmol} / /$ had sensitivity of $70.49 \%$ and specificity of $100.00 \%$ in diagnosing GDM. An FPG cut-off value of $\leq 4.5 \mathrm{mmol} / \mathrm{l}$ had sensitivity of $93.44 \%$ and specificity of $67.6 \%$ in diagnosing GDM. Undergoing an initial FPG could have saved $67.7 \%$ of these women from taking the OGTT and only $1.5 \%$ (4 of the 264 ) would have been misclassified.

Conclusion: Screening using an initial FPG rule-in and rule-out algorithm reduces the number of OGTTs needed for the diagnosis of GDM. Almost all GDM pregnancies can be diagnosed.
\end{abstract}

Pam Med J 2013;6(3):122-126

Key words: GDM, diagnosis, fasting plasma glucose, OGTT

Özet

Amaç: Gestasyonel diabetes mellitus (GDM) tanısı için gerekli Oral glukoz tolerans testi (OGTT) sayısını sınırlamak için açlık plazma glikozun (APG) kullanımı değerlendirmektir.

Gereç ve yöntem: Tahmini gebelik yaşları 24-28 hafta arasında 390 gebe GDM açısından değerlendirildi. Tanı için OGTT'e dayalı International Association of Diabetes and Pregnancy Study Group (IADPSG) kriterleri kullanıldı. Íki APG eşik değeri GDM' nin ekarte edilmesi ve dahil edilmesi için kullanıldı.

Bulgular: Katılımcıların 61 (\%15.6)'i GDM tanısı aldı. GDM tespit etmek için kullanılan APG'nin ROC eğrisi altında kalan alan 0.933 oldu. GDM tanısı için APG'nin $\geq 5.1 \mathrm{mmol} /$ eşik değer kullanıldığında sensitivite $\% 70.49$ ve spesifite $\% 100.00$ oldu. APG'nin $\leq 4.5 \mathrm{mmol} / \mathrm{l}$ eşik değer kullanıldığında sensitivite $\% 93.44$ ve spesifite $\% 67.60$ oldu. Başlangıç APG'nin kullanılması OGTT intiyaçını \%67,7 oranında azalmaktadır ve sadece \%1,5'i yanlış sınıflandırılmaktadır.

Sonuç: GDM tanısı için AFP'nin alt ve üst eşik değerlerinin kullanılması OGTT intiyacını azaltmaktadır. Bu yöntemle GDM hastalarının hemen hemen tümü tanınabilmektedir.

Pam Tıp Derg 2013;6(3):122-126

Anahtar sözcükler: GDM tanısı, açlık plazma glukoz, OGTT

Osman Şevket

Yazışma Adresi: Haseki Eğitim Ve Araştırma Hastanesi, Enfeksiyon Hastalıkları ve Klinik Mikrobiyoloji, İstanbul e-mail: sevketosman@gmail.com 


\section{Introduction}

Gestational diabetes mellitus (GDM) is defined as carbohydrate intolerance that begins or is first recognized in pregnancy [1]. GDM is one of the most common medical complications of pregnancy, with an overall prevalence of $3-5 \%$, but as high as $18 \%$ depending on the population and diagnostic criteria. The oral glucose tolerance test (OGTT), although the gold standard test for diagnosing GDM [2-4], is inconvenient, unpleasant, poorly reproducible, expensive, time consuming, and unsuitable for large-scale screening. In addition, it requires at least $2 \mathrm{~h}$ for sample collections and a minimum two blood samples are needed.

On the other hand, fasting plasma glucose (FPG) is inexpensive, reproducible, and easy to perform. Because of the varied results in different populations, however, the efficacy of FPG as a screening test in pregnancy remains unclear [5]. For example, in the HAPO study using the International Association of Diabetes and Pregnancy Study Group (IADPSG) diagnostic criteria, $51 \%$ of GDM was diagnosed by an FPG $>5.1 \mathrm{mmol} / \mathrm{L}(92 \mathrm{mg} / \mathrm{dl})$ [6]. This prospective study evaluates the utility of initial FPG with the goal of limiting the number of OGTTs needed for the diagnosis of GDM.

\section{Materials and Methods}

This study was a prospective observational study conducted from May 2011 to November 2012 at the Department of Obstetrics and Gynecology, Bezmialem Vakif University, Istanbul, Turkey. We excluded women who had multiple pregnancies, those with pregestational diabetes mellitus, those with fetal anomalies diagnosed prenatally, those who delivered prior to the 28-week gestation, and those who did not follow the protocol. The study protocol was approved by the Research and Ethics Committee of Bezmialem Vakif Hospital.

During the study period, all pregnant women between 24 and 28 weeks of gestation who had been referred for GDM screening were informed about the study by their obstetricians. Women who agreed to participate in the study signed an informed consent and were asked to come to the hospital in a fasting state. Venous blood samples were then collected three times: after 8 to 12 hours of overnight fasting, 1 hour after ingesting $75 \mathrm{~g}$ of glucose, and 2 hours after ingesting $75 \mathrm{~g}$ of glucose. The patients received the diagnosis of GDM if their $2 \mathrm{~h}$ OGTT results met one of the following thresholds of the IADPSG criteria: a fasting glucose $\geq 5.1 \mathrm{mmol} / \mathrm{L}$ (92 $\mathrm{mg} / \mathrm{dl})$, a 1 hour plasma glucose $\geq 10 \mathrm{mmol} / \mathrm{L}$ $(180 \mathrm{mg} / \mathrm{dl})$, or a 2 hour plasma glucose $\geq 8,5$ $\mathrm{mmol} / \mathrm{L}(153 \mathrm{mg} / \mathrm{dl})$ [4]. Women classified as GDM were then referred to an endocrinologist, received a glucose monitoring device, and were assigned a special diet (treatment) and, if needed, medication. Plasma glucose was estimated by the glucose oxidase method.

A rule-in and rule-out algorithm was used to evaluate the utility of initial FPG to limit the number of OGTTs needed for the diagnosis of GDM [7]. Briefly, this approach involves considering two FPG threshold values. The higher threshold, with an inherently increased specificity, rules in GDM; the lower threshold, with its innate increased sensitivity, rules out GDM. Women who have FPG values in between these two thresholds are indeterminate and would need the diagnostic OGTT.

\section{Statistical analyses}

T-tests were performed to test the difference between two means. The ROC curve was drawn to determine sensitivity and specificity. All statistical analyses were performed using SPSS Statistics version 17.0 software.

\section{Results}

The mean maternal age, parity, BMI, and gestational week of the 390 pregnant women were $27.8 \pm 4.8$ years, $0.9 \pm 0.9,25.4 \pm 4.0 \mathrm{~kg} /$ $\mathrm{m} 2$, and $25.7 \pm 1.0$, respectively.

Using the IADPSG criteria, 61 (15.6\%) of the participants had GDM.

High FPG was seen in the 28 participants, high 1-h plasma glucose levels was revealed in 11 of the participants, high 2-h plasma glucose occurred in 4 of the participants, high FPG and 1-h plasma glucose levels were found in the 10 participants, high FPG and 2-h plasma glucose levels elicited in the 2 participants, high 1-h plasma glucose and 2-h plasma glucose levels were manifested in 4 of the participants, and 2 of the participants presented with high FPG and 1-h plasma glucose and 2-h plasma glucose levels. 
Using the IADPSG criteria, 61 (15.6\%) of the participants had GDM. The mean \pm SD FPG value in women with GDM was $96.13 \pm 18.21$ and $78.38 \pm 6.65$ in women without GDM, a statistically significant difference $(p=0.00)$. The ROC curve (Fig. 1) was drawn to determine the sensitivity and specificity of FPG in detecting GDM. The area under the ROC curve of FPG to detect GDM was $0.933(95 \% \mathrm{Cl} 0.903-0.956)$. The higher threshold $(5.1 \mathrm{mmol} / /(92 \mathrm{mg} / \mathrm{dl}))$, and the lower threshold $(4.5 \mathrm{mmol} / /(81 \mathrm{mg} /$ dl)) was chosen based on data from our ROC curve and data from the HAPO study. An FPG cut-off value of $\geq 5.1 \mathrm{mmol} / /(92 \mathrm{mg} / \mathrm{dl})$, had sensitivity of $70.49 \%$ and specificity of $100.00 \%$ in diagnosing GDM. An FPG cut-off value of $\leq 4.5 \mathrm{mmol} / \mathrm{l}(81 \mathrm{mg} / \mathrm{dl})$ had sensitivity of $93.44 \%$ and specificity of $66.77 \%$ in diagnosing GDM.

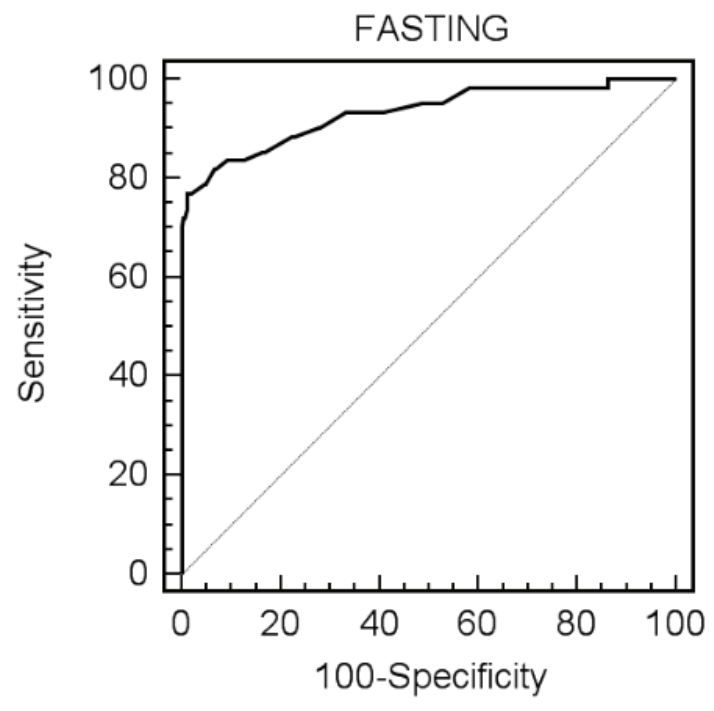

Figure 1. ROC curve showing the sensitivity and specificity of FPG in detecting GDM using IADPSG criteria.

\section{Discussion}

In March 2010, the International Association of Diabetes and Pregnancy Study Group (IADPSG) issued concensus guidelines with the goal of potentially attaining a single approach for GDM diagnosis worldwide [4], recommending that every pregnant woman should undergo the OGTT, a costly and cumbersome test for both the patient and the health provider. To decrease the need of the extremely demanding OGTT, as an alternative approach we here evaluate the use of initial FPG. A two threshold rule-in and rule-out algorithm was used for this purpose.
In our study using the IADPSG diagnostic criteria, $70.4 \%$ (11.02\% of the total population) of GDM was diagnosed by an $\mathrm{FPG} \geq 5.1 \mathrm{mmol} / \mathrm{L}$ (92 $\mathrm{mg} / \mathrm{dl})$, whereas $51 \%$ and $40 \%$ of GDM was diagnosed by an FPG $>5.1 \mathrm{mmol} / \mathrm{L}(92 \mathrm{mg} /$ dl), in the HAPO study and that of Mahdavian et al., respectively [6.8]. In our view, FPG $\geq$ $5.1 \mathrm{mmol} / \mathrm{L}(92 \mathrm{mg} / \mathrm{dl})$, may be sufficient to diagnose the majority of women with GDM.

The number of OGTTs avoided is dependent on the criteria used for GDM diagnosis (Table 1) [9-14]. In this study, using the new IADPSG criteria, the FPG $\geq 5.1 \mathrm{mmol} / \mathrm{L}(92 \mathrm{mg} /$ dl) value, the higher threshold with an inherently increased specificity $(100 \%)$ and FPG $\leq 4.5$ $\mathrm{mmol} / \mathrm{L}(81 \mathrm{mg} / \mathrm{dl})$ value, the lower threshold with its innate increased sensitivity (93.44\%), was used to limit the number of OGTTs needed for the diagnosis of GDM. Using FPG as the initial test, if the level of $F P G \geq 5.1 \mathrm{mmol} / \mathrm{L}$ (92 $\mathrm{mg} / \mathrm{dl}$ ), then the women can be labeled as having GDM. If the level of FPG $\leq 4.5 \mathrm{mmol} / \mathrm{L}$ $(81 \mathrm{mg} / \mathrm{dl})$, then the women can be labeled as normal. For women with FPG levels between $4.5 \mathrm{mmol} / \mathrm{L}(81 \mathrm{mg} / \mathrm{dl})$, and $5.1 \mathrm{mmol} / \mathrm{L}(92 \mathrm{mg} /$ dl), an OGTT should be performed to correctly identify those with GDM (Fig. 2). Using the two cut-off approach, a higher FPG threshold of $\geq 5.1 \mathrm{mmol} / \mathrm{l}(92 \mathrm{mg} / \mathrm{dl})$, ruled in GDM in 44 women. A lower FPG threshold of $\leq 4.5 \mathrm{mmol} / \mathrm{l}$ $(81 \mathrm{mg} / \mathrm{dl})$, ruled out GDM in 220 women. Using this methodology, $93.5 \%$ of the GDM cases would have been detected, thereby obviating an OGTT for $67.7 \%$ the women in our study.

In the Agarwal et al. study, $4.6 \%$ of GDM cases would have been missed while $23 \%$ of women with GDM would have been misclassified as healthy in the study of Mahdavian et al. by not performing OGTT for women whose FPG < $4.4 \mathrm{mmol} / \mathrm{l}(80 \mathrm{mg} / \mathrm{dl})$, [8.14]. In our study, the women those level of FPG $\leq 4.5 \mathrm{mmol} / \mathrm{l}(81 \mathrm{mg} /$ $\mathrm{dl}$ ), could be labeled as normal and only $1.5 \%$ of those with GDM were misclassified as healthy. Reasons for such discordant results probably were associated with ethnicity and higher baseline insulin resistance in Turkish women.

One limiting factor for this approach is laboratory turnaround time for the initial FPG result, i.e., the time the pregnant woman has to wait in a fasting state. Furthermore, generally all women have to await results of their FPGs in order to rule out overt diabetes mellitus. 
Table 1. Reports the number avoided of OGTT dependent on the criteria used for GDM diagnosis.

\begin{tabular}{|c|c|c|c|c|c|}
\hline Reference & $\begin{array}{l}\text { No. of OGTTs } \\
\text { circumvented, } \%\end{array}$ & $\begin{array}{l}\text { Thresholds (lower } \\
\text { and higher) mmol/ }\end{array}$ & OGTT & $\begin{array}{l}\text { Diagnostic } \\
\text { criteria }\end{array}$ & Comments \\
\hline $\begin{array}{l}\text { Agarwal et al. } \\
(2000)^{9}\end{array}$ & 50.9 & 4.4 and 5.3 & $100 \mathrm{~g}$ & ADA & $\begin{array}{l}\text { Biased sampling: } \\
\text { Preselected by clinical/GCT }\end{array}$ \\
\hline $\begin{array}{l}\text { Agarwal et al. } \\
(2005)^{10}\end{array}$ & 30.1 & 4.7 and none & 75 & WHO & $\begin{array}{l}\text { FPG performance poor with } \\
\text { WHO criteria }\end{array}$ \\
\hline $\begin{array}{l}\text { Agarwal et al. } \\
(2008)^{11}\end{array}$ & 68.5 & 4.9 and 7.0 & 75 & $A D A$ & Glucometer used for FPG \\
\hline $\begin{array}{l}\text { Agarwal et al. } \\
(2006)^{12}\end{array}$ & 63.8 & 4.9 & 75 & $A D A$ & $\begin{array}{l}\text { FPG screening criteria } \\
\text { dependent }\end{array}$ \\
\hline $\begin{array}{l}\text { Agarwal et al. } \\
(2009)^{13}\end{array}$ & 50.1 & 4.7 and 7.0 & 75 & ADA & $\begin{array}{l}\text { Fasting capillary glucose } \\
\text { used }\end{array}$ \\
\hline $\begin{array}{l}\text { Agarwal et al. } \\
(2010)^{14}\end{array}$ & 50.6 & 4.4 and 5.1 & 75 & IADPSG & Data from four studies \\
\hline $\begin{array}{l}\text { Mahdavian et al. } \\
(2010)^{8}\end{array}$ & 40 & 4.4 and 5.1 & 75 & IADPSG & $\begin{array}{l}\text { FPG performance poor with } \\
\text { IADPSG criteria }\end{array}$ \\
\hline $\begin{array}{l}\text { Results of our } \\
\text { study }\end{array}$ & 67.7 & 4.5 and 5.1 & 75 & IADPSG & $\begin{array}{l}\text { FPG performance good with } \\
\text { IADPSG criteria }\end{array}$ \\
\hline
\end{tabular}

FPG at 24-28 weeks gestation

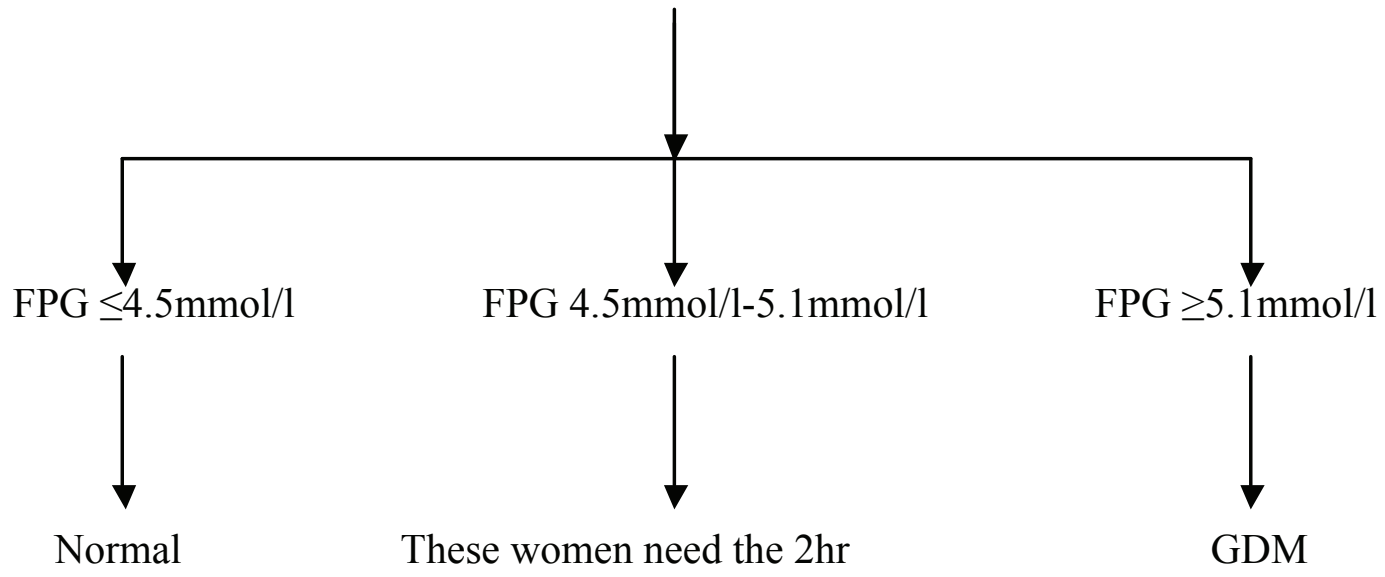

OGTT to determine whether

they have GDM or not

Figure 2. Flow diagram showing utility of initial FPG along with OGTT in order to diagnose GDM per IADPSG criteria

We have shown that the initial FPG identifies the majority of GDM pregnancies in our population. Using the initial FPG rule-in and rule-out algorithm for GDM dignosis, almost all GDM pregnancies can be diagnosed, thereby decreasing the need of OGTT by $67.7 \%$. Considering laboratory costs and workload [15], making use of an initial FPG is an advantageous approach, both effective and efficient, so that it will be proportionate to expected risk.
Conflict of Interest: The authors report no conflict of interest.

\section{References}

1. ACOG Practice Bulletin. Clinical management guidelines for obstetrician-gynecologists. Number 30, September 2001 (replaces Technical Bulletin Number 200, December 1994). Gestational diabetes. Obstet Gynecol 2001;98:525-538.

2. American Diabetes Association (ADA). Gestational diabetes mellitus. Diabetes Care 2004;27 (Suppl 1):S88-S90. 
3. WHO. Definition, diagnosis and classification diabetes and its complications. Part 1: diagnosis and classification of diabetes mellitus. Report of WHO consultation, Geneva: World Health Organization, 1999.

4. Metzger BE, Gabbe SG, Persson B, et al. International Association of Diabetes and Pregnancy Study Groups recommendations on the diagnosis and classification of hyperglycemia in pregnancy. Diabetes Care 2010;33:676-682.

5. Hanna FWF, Peters JR. Screening for gestational diabetes; past, present and future. Diabet Med 2002;19:351-358.

6. Metzger BE, Lowe LP, Dyer AR, et al. Hyperglycemia and adverse pregnancy outcomes. N Engl J Med 2008;358:1991-2002.

7. Henderson AR. Assessing test accuracy and its clinical consequences: a primer for receiver operating characteristic curve analysis. Ann Clin Biochem 1993;30:521-539.

8. Mahdavian M, Hivert MF, Baillargeon JP, Menard J, Ouellet A, Ardilouze JL. Gestational diabetes mellitus: simplifying the international association of diabetes and pregnancy diagnostic algorithm using fasting plasma glucose: comment on Agarwal, Dhatt, and Shah. Diabetes Care. 2010;33:145.

9. Agarwal MM, Hughes PF, Punnose J, Ezimokhai M. Fasting plasma glucose as a screening test for gestational diabetes in a multi-ethnic, high-risk population. Diabet Med 2000;17:720-726.
10. Agarwal MM, Dhatt GS, Punnose J, Koster G. Gestational diabetes in a high risk population: using the fasting plasma glucose to simplify the diagnostic algorithm. Eur J Obstet Gynecol Reprod Biol 2005;120:39-44.

11. Agarwal MM, Dhatt GS, Safraou MF. Gestational diabetes: using a portable glucometer to simplify the approach to screening. Gynecol Obstet Invest 2008;66:178-183.

12. Agarwal MM, Dhatt GS, Punnose J. Gestational diabetes: utility of fasting plasma glucose as a screening test depends on the diagnostic criteria. Diabet Med 2006; 23:1319-1326.

13. Agarwal MM, Dhatt GS, Othman Y, Gupta R. Gestational diabetes: fasting capillary glucose as a screening test in a multi-ethnic, high-risk population. Diabet Med 2009;26:760-765.

14. Agarwal MM, Dhatt GS, Shah SM. Gestational diabetes mellitus: simplifying the international association of diabetes and pregnancy diagnostic algorithm using fasting plasma glucose. Diabetes Care 2010;33:20182020.

15. Agarwal MM, Dhatt GS, Othman Y. Gestational diabetes in a tertiary care hospital: implications of applying the IADPSG criteria. Arch Gynecol Obstet 2012;286:373-378. 